\title{
Renewable Energy Production Forecasting: A Comparative Machine Learning Analysis
}

\author{
Kazi Md Shahiduzzaman, Md Noor Jamal, Md. Rashed Ibn Nawab
}

\begin{abstract}
As renewable energy has become increasingly popular worldwide, while solar and wind energy has been the leading source of renewable energy up to now, the accuracy of renewable energy forecasts is challenge for the planning, management, and operations of the power system. However, due to the intermediate and frenzied nature of renewable energy data, this is a most challenging task. This study provides a comprehensive and complete review of the renewable energy forecast based on different machine learning algorithms to explore effectiveness, efficiency, competence, and application potential. In this work, we have built time series renewable energy forecasting model with Support Vector Machine (SVM), Linear Regression (LR), and Long Short-Term Memory (LSTM) on twelve (12) countries. The experimental results are very interesting. For example, SVM based forecasting model is a better fit for the countries with small mean and standard deviation while linear regression-based methods show a bit better result in case of larger mean and standard deviation. Meanwhile, LSTM based models provide smoother regular-shaped forecasting. We can forecast two years of daily renewable energy production with these forecasting models. The point should be noted that we have developed different models for different countries. We have able to reach a Root Mean Square (RMS) value of 3.138 with SVM based model.
\end{abstract}

Keywords: Renewable Energy Forecasting, Support Vector Machine (SVM), Linear Regression (LR), Long Short-Term Memory (LSTM), Time Series Forecasting.

\section{INTRODUCTION}

Renewable energy sources are widely available and have the potential to meet the energy needs of the entire human race. However, combining such energy sources to produce energy is not an easy process for several reasons, including breaks. Interstate creates a difference in energy production which implies that timing, climate change, changing weather conditions, and geographical location are affected in the term of power generation from the power source. The reduction of fossil fuels has increased environmental pollution, and the

Manuscript received on May 24, 2021.

Revised Manuscript received on July 19, 2021.

Manuscript published on August 30, 2021.

* Correspondence Author

Kazi Md Shahiduzzaman *, Department of Electrical and Electronic Engineering, Jatiya Kazi Nazrul Islam University, Mymensingh, Bangladesh. Email: shahiduzzaman@jkkniu.edu.bd

Md Noor Jamal, School of Electronics, Information and Communication, Huazhong University of Science and Technology, Wuhan, China. Email: noorjamal97531@gmail.com

Md. Rashed Ibn Nawab, School of Computer Science and Technology, Northwestern Polytechnical University, China. Email: rashednawab@outlook.com

(c) The Authors. Published by Blue Eyes Intelligence Engineering and Sciences Publication (BEIESP). This is an open access article under the CC BY-NC-ND license (http://creativecommons.org/licenses/by-nc-nd/4.0/) development and maximum use of renewable energy sources have concerned the attention of experts and scholars around the world [1-2]. Sustainable change is a long-term, multidimensional, and fundamental transformation process, and is one of the major challenges of the 21st century. Since non-polluting renewable energy sources are high value in many countries. Solar and wind power generation have debuted as the most mature renewable power generation technologies including high commercialization potential.

In recent years, Machine learning as a promising branch of Deep learning has attracted much attention [3] due to three major attributes, i) strong generalization capability, ii) unsupervised feature learning and iii) big-data training. It is naturally a kind of alternative of shallow models and has been widely implemented in pattern recognition, image processing, fault detection, classification, and forecasting tasks [4]. The obtained features are very informative and suitable for solar and wind energy forecasting. Chang et al. proposed a new integrating method based on grey theory and deep belief network for day ahead photovoltaic power output, demonstrating that the forecast accuracy and computational efficiency are superior to the benchmarks [5]. In [6] developed a new deep machine learning algorithm to predict short-term wave energy. The forecasting results are useful for real-time control and optimal wave energy management. The simulation shows that the prediction error has a negative impact on the model predictive control performance, resulting in a decrease in wave energy absorption. In addition, deep recurrent neural networks, deep convolutional neural network, and stacked extreme learning machine [7] have also been frequently reported for renewable energy forecasting. It is generally recognized that deep learning-based forecasting models exhibit attractive performance in terms of accuracy, stability, and effectiveness [8], which are beneficial to energy system planning, scheduling, and management [9]. Up to date, statistics show that more concentrated on deep learning-based forecasting models.

Renewable Energy Resources (RES) todays has made energy forecasting popular. It is very important for the network operator and decision making to know how much renewable energy resources will produce in the next hours and days. In addition, forecasting load demand and consumption play an important role in the management and planning of modern systems. When the demand for additional power generation and load from the RES is low, the need for conservation of power is required. However, because energy storage is expensive, it requires high maintenance and has a limited life span and cannot be widely stored. Because of this, utilities have to supply balance and demand at every moment.

Published By:

Blue Eyes Intelligence Engineering and Sciences Publication 
These limitations lead to several interesting energy forecasting features, which included the need for accurate accuracy and data collection. Forecasting errors lead to unbalanced demand for the supply, which adversely affects operating costs, efficiency, and reliability. Forecasting energy production and consumption are frequently based on meteorological data like temperature, solar irradiation, and the number of occupants and appliances respectively. However, there are cases where on-site measures of wind and solar irradiation are not possible and other meteorological variables such as temperature and humidity are not accessible and only historical statistics are available. In such cases, data-driven models can be used for forecasting.

The concept of combining forecasts started with the study in [10], which claimed that a suitable linear combination of forecasts achieves higher forecasting accuracy than a policy of trying to find and use the best single forecast, in the case of a smaller variation of errors. Applications of combining forecasts have been reported over the years in many fields such as size, environment, insurance, meteorology, and sales forecasting.

The combination of wind and solar forecasts becomes a matter of obtaining a final single forecast output when multiple forecast results are present, as discussed. Accordingly, an individual forecast may not always be satisfactorily output, while an integrated forecast can produce better result. Thus, studying solar power, wind power, and forecasting not only use multiple sources in their proposed forecasting method, but also different processes in a particular source. Then, they try to combine all the applied predictions instead of choosing the best one.

Combining several wind power predictions is valuable in exploiting the fact that each forecast model has strengths in different situations [18]. Ideally, forecast must be better than the individual predictions, or at least equal to the best-performed forecast to be considered a successful combination of forecasts.

In thi`s article we have compare between different machine learning algorithms for generation of renewable energy over a daytime period with the highest accuracy. Therefore, this provides the most accurate and efficient power dispatch for energy management systems. The following Figure 1 depicts our idea.

The purpose of this study to understand the production prediction forecasting and calculate the less error. The algorithms introduced in this paper automatically search the space of candidate models. The model space includes machine learning models such as Support Vector Machine (SVM), Linear Regression (LR), and Long Short-Term Memory (LSTM). An overview of the time series renewable energy forecasting model and machine learning techniques are presented. The search algorithm often defines the properties of the model including layout, order and parameter values. The main contributions of this research are listed below:

- To determine production prediction forecasting.

- Can easily Provide exploratory algorithm based on problem optimization.

- $\quad$ Evaluate the performance of the compacted model.

- Determine the minimum less error.

\section{LITERATURE REVIEW ON PRODUCTION FORECASTING OF RENEWABLE ENERGY}

Since renewable energy has become increasingly popular worldwide, while wind and solar still are the leading sources of renewable energy, proper improvement of renewable energy forecasts is important for, operating and managing power systems planning. However, due to the intermediate and promiscuous nature of renewable energy data, this is a most challenging task. To date, artificial intelligence techniques, statistical methods, physical models, and their hybrids, have been developed to improve the exactitude of forecasting renewable energy. The need for renewable energy sources arises from the recognition of the measurable supply of fossil fuels, the rising cost of fossil fuels, and the pollution caused by fossil fuels. Despite these problems, fossil fuels still dominate the fuel market, producing more than $5 \%$ of global production. Energy obtained from fossil fuels is limited and nonrenewable which means these energy resources are becoming scarcer and more expensive.

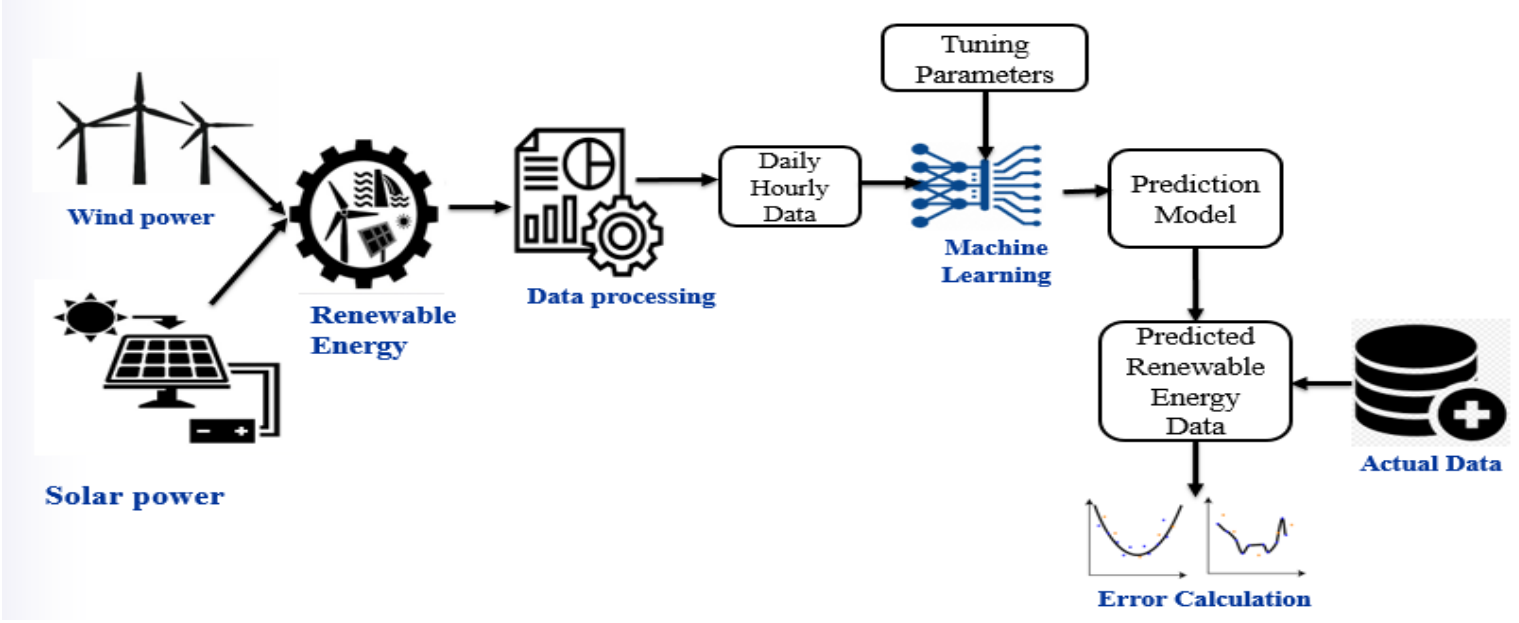

Figure 1: Renewable Energy Forecasting Model

Published By:

Blue Eyes Intelligence Engineering and Sciences Publication (C) Copyright: All rights reserved.

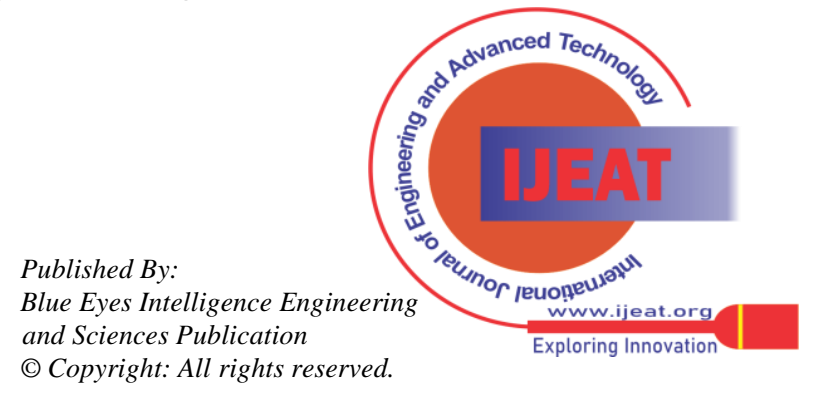


Global energy demand will continue to rise even after scarcity and cost increases. Global energy demand is expected to increase by $45 \%$ worldwide, and electricity demand will increase by $80 \%$ between 2006 and 2030. The developed countries have an expected 5\% annual energy growth rate and the expected 5\% annual energy growth rate. The studies 11 show that worldwide the solar energy capacity has expanded from $1.28[\mathrm{GW}$ ] to 138.86 [GW]. Based on 12, the contribution of concentrated solar power is supposed to be around $5 \%$ of the annual global electricity generation. Until 2030 a 5\% rising of photovoltaic production to global energy production is anticipated and a percentage of $11 \%$ is targeted for 2050 13, 14
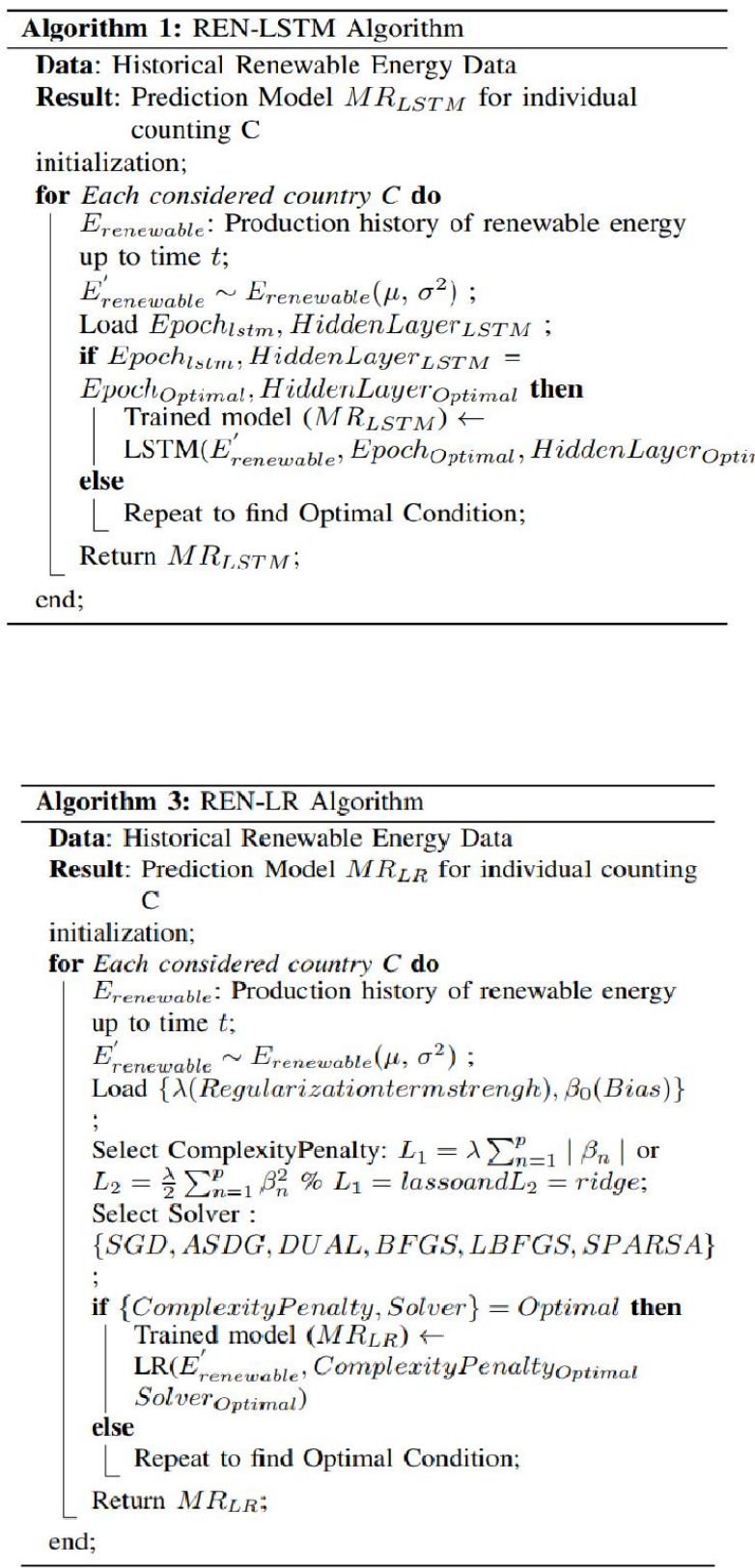
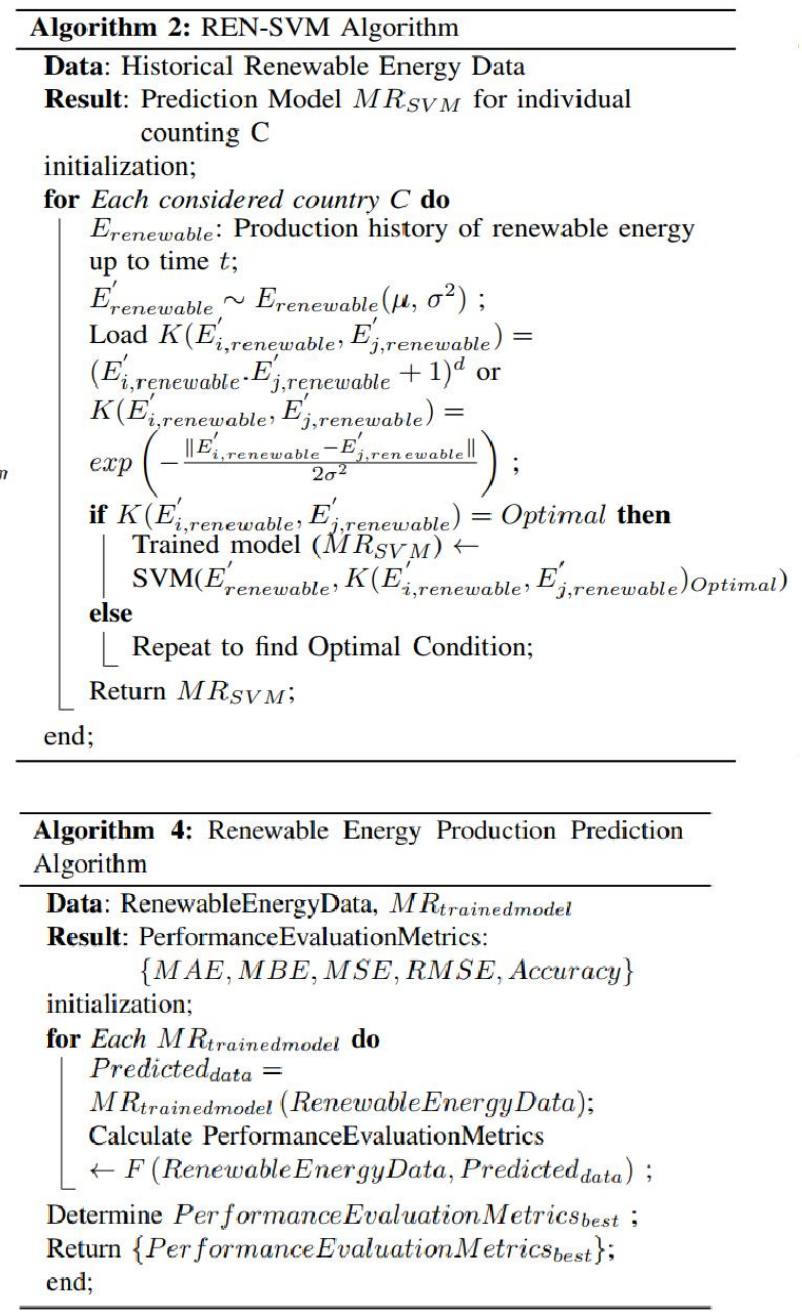

Figure 2: Proposed REN algorithm for renewable energy prediction.

In theory, the Earth holds enough wind potential to reencounter the energy demands of the world. In almost every country there are enough wind speeds sufficient for energy production. Various limitations such as financing, environmental concerns, appropriate site landscapes, and available technology make the potential for global wind energy development difficult. In addition to these constraints, the wind is a variable that is extremely variable and random 16. Although from an environmental point of view, wind energy is praised as superior to fossil fuels, it does not come without some apprehensions and limitations. Despite the widespread popularity of the wind energy industry, some

obstacles still need to be overcome. The noise from the turbines, the risk of wildlife, the interference of television, the dangers of aircraft, and the aesthetic degradation of the landscape are some of the factors that influence public opinion on wind power development 17 . Additionally, wind energy from a single region cannot be relied on to provide baseload energy, as wind speed varies throughout the day as well as the season.

Published By:

Blue Eyes Intelligence Engineering and Sciences Publication (C) Copyright: All rights reserved.

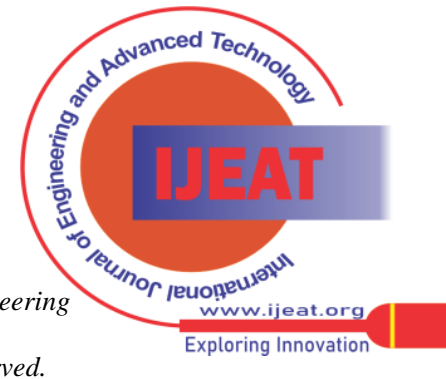


Therefore, it is essential to develop a predictive model for renewable energy production. Here, we have considered the combination of solar and wind energy as renewable energy. Our proposed model can generate production prediction for two years on daily basis. The outcome of this model will be very helpful for the electrical energy distribution, cost calculation, load distribution design in advance. This prediction model will also help the renewable energy engineer to develop more efficient solar cell and wind turbine.

\section{PROPOSED REN FOR RENEWABLE ENERGY PRODUCTION PREDICTION}

The main contribution of this work is to develop prediction model for renewable energy production by using Long Short-Term Memory (LSTM), Support vector Machine (SVM) and Linear Regression (LR). The proposed REN algorithm is depicted in algorithms in First three algorithms in algorithms in, show how we have developed the training model and the fourth algorithm explain how to achieve the optimal prediction result. We have developed each algorithm for training model in such a way that it can use optimal input argument and decide the appropriate training model for each country. In this way, the REN prediction system can achieve high efficiency in combine renewable energy of solar and wind over two years prior on daily basis. The fourth algorithm is used to select the best algorithm fitted for different country. The REN algorithm has the intelligence not only to select the appropriate machine learning algorithm but also the input argument for each method. In this way, this algorithm can achieve high accuracy. For developing the trained network, it compared and validate few machine and deep learning algorithm with optimal input arguments in terms of mean absolute error (MAE), mean forecasting error (MFE), mean square error (MSE), root mean square error (RMSE) and overall system accuracy. The REN prediction system returns the most effective trained network for predicting data.

\section{DATA SOURCE AND MODIFICATION}

This section will discuss a brief about the considered data source and a detail discussion on the data modification technique. We have considered EMHIRES dataset for solar 18 and wind 19. These two datasets represent the hourly solar and wind energy production over 15 years' time on 30 European countries.

\section{A. Original Data Sources}

In the study of 18 , the authors used PVGIS model to convert solar resources in power generation. In this process, the solar radiation satellite-based data is converted into radiation on inclined plane. Then, electrical power in $\mathrm{kW}$ (kilowatts) is calculated from radiation. Finally, to obtain the power generation the installed capacity of each region is calculated and then, the time series are corrected with the TSO actual generation and statistically validated for power system analysis, by assessing the power peaks and ramps, duration curves and capacity factors. EMHIRES solar provides RES-E (Renewable energy sources for the generation of electricity) hourly generation time series for the EU-28 and neighboring countries. The solar power time series are released at hourly granularity and at different aggregation levels: by country, power market bidding zone, and by the European Nomenclature of territorial units for statistics
(NUTS) defined by EUROSTAT; in particular, by NUTS 1 and NUTS 2 level. The time series provided by bidding zones include special aggregations to reflect the power market reality where this deviates from political or territorial boundaries.

The wind farms database procured from the 'thewindpower.net' 20 has been used as the primary source to define the characteristics of each wind farm included in EMHIRES. But the original data has some inconsistencies, inaccuracies, and gap. That is why the authors in 19 use gap filling and homogenization to reconstruct the data. EMHIRES contains wind power at hourly frequency covering a period of 30 years over Europe, calibrated ex post with measurements. Therefore, the calculated wind power time series in EMHIRES are validated against the actual wind power generation outputs provided by the Transmission System Operators (TSOs).

\section{B. Data Modification}

In this research, we have considered daily renewable energy production prediction. So, we have converted data from hourly to combine daily and then. We have used the following simple equation Eqn.(1) for the conversion

$$
\left.\begin{array}{c}
\text { Energy }_{\text {Solar_Daity }}=24 \times \text { Energy }_{\text {Sotar_Hourty }} \\
\text { Energy }_{\text {wind_Daity }}=24 \times \text { Energy }_{\text {wind_Hourly }} \\
\text { Energy }_{\text {Daily }}=E_{\text {Energy }} \\
\text { wind_Daily } \\
+ \text { Energy }_{\text {Solar_Daily }}
\end{array}\right\}
$$

For this research work we have only considered Austria, Belgium, Czech, Finland, France, Germany, Ireland, Netherland, Norway, Poland, Sweden, and Spain. Because these countries produce significant amount of renewable energy through solar and wind. After the data modification we have a data file containing three variables, first one is Energy $y_{\text {wind Daily, }}$, second one is Energy $y_{\text {Solar Daily }}$, and the last one is Energy $y_{\text {Daily }}$ which is explained in Eqn.(1). All data are saved in .xls format. Each .xls file has 3 columns and 10957 rows. As each of the represent daily information, therefore we can easily figure out time information from these .xls files. The moderated dataset can be found in the following website:

https://www.kaggle.com/kazimdshahiduzzaman/dataset-fo r-ren-algorithm

\section{PERFORMANCE EVALUATION OF THE REN ALGORITHM}

In this part, we will discuss about the experimental results and evaluate the performance of the proposed REN algorithm. Here, we will present a brief about the performance of the proposed model. Then, the statistical behavior of the predicted data will be highlighted. We will start our discussion with performance evaluating metrics and the experimental setup.

\section{A. Performance Evaluating Metrics}

- Mean Forecast Error (MFE): It is a measure of the average deviation of forecasted values from actual data.

Published By:

Blue Eyes Intelligence Engineering and Sciences Publication (C) Copyright: All rights reserved. 
- Mean Absolute Error (MAE): MAE measures the average absolute deviation of forecasted original values.

- Mean Squared Error (MSE): The important feature is a measure of the average squared deviation of forecasting values. The signed errors in the opposite direction don't balance each other, MSE gives an overall indication of the mistake that occurred.

- Root Mean Square Error (RMSE) RMSE is a frequently used measure of the differences between values (sample or population values) predicted by a model or an estimator and the values observed.

- Accuracy: The accuracy represents how efficiently the proposed method can forecast the renewable power generation. The accuracy is calculated from the mean absolute error.

Table 1: Considered methods and their properties.

\begin{tabular}{|l|l|l|l|}
\hline & LSTM & SVM & Linear regression \\
\hline \multirow{2}{*}{ Properties } & $\begin{array}{l}\text { No. of Hidden Unit: } 200 \\
\text { Maximum Epoch: } 250\end{array}$ & Data Standardize & Kernel Function: Gaussian \\
& $\begin{array}{l}\text { Gradient Threshold: } 1 \\
\text { Initial Learning Rate: } 0.05 \%\end{array}$ & $G\left(x_{j}, x_{k}\right)=\exp \left(-\left\|x_{j}-x_{k}\right\|^{2}\right)$ & $\begin{array}{l}\text { Learner: Least Square } \\
\end{array}$ \\
& & & \\
\hline
\end{tabular}

\section{B. Technical evaluation of the Pre-Processed Data}

Before we start our experimental evaluation, we must talk about the data pre-processing. After modifying the original dataset, we have selected top twelve countries in Europe where renewable energy is the major source for electricity production. To minimize the error, we have normalized the to 0 mean and 1 standard deviation. The data become smooth. The mean and standard deviation is shown by Table 2 .

Table 2: Statistical properties (mean and standard deviation) of the considered data

\begin{tabular}{|c|c|c|}
\hline Country & Mean (mu) & Standard Deviation (Sigma) \\
\hline Austria & 30.813 & 16.354 \\
\hline Belgium & 33.781 & 22.137 \\
\hline Czech & 26.043 & 16.739 \\
\hline Finland & 6.680 & 5.694 \\
\hline France & 76.601 & 35.333 \\
\hline Germany & 67.931 & 40.924 \\
\hline Ireland & 7.102 & 4.588 \\
\hline Netherland & 36.118 & 23.829 \\
\hline Norway & 12.647 & 10.349 \\
\hline Poland & 47.844 & 30.418 \\
\hline Sweden & 16.825 & 12.782 \\
\hline Spain & 70.551 & 22.353 \\
\hline
\end{tabular}

\section{Experimental Setup}

In this work, we have used an intel core i5 platform with 8 GB RAM. We have considered thirteen (13) years' data as input to the considered machine learning technique and predict two years of daily renewable energy production. The number of train data is 10227 i,e, the train data represent 10277 days' daily renewable energy production. This includes both wind and solar energy. We have predicted the next 730 days' renewable energy production. For machine learning technique, we have considered Long Short-Term Memory (LSTM), Support Vector Machine (SVM) and
Linear regression (LR). The properties I have considered is given by the following

\section{Experimental Result and Evaluation}

As we have mentioned that REN is going to select the optimized algorithm with optimal input parameter from LSTM, SVM and Linear regression for predicting renewable energy in advance. In this study we would predict daily data for two years in advance. It can be easily seen from that both SVM and Linear regression process are able to generate close prediction than LTSM. It is clearly indicated that SVM performs the best for the most country. While Linear regression-based algorithm provides sufficient effective result. In case of Finland and Sweden LR provide the best and accurate result. The training time is another factor of consideration. LSTM takes much time to train the network and predict the data. Linear regression-based models are most lightweight. It takes least amount of time. But time taken by SVM based model can also be considered as less. Model based on SVM are also lightweight. So, the REN can predict 2 years renewable power generation with sufficient accuracy. Here, we will only present the visual results for Sweden and Spain.

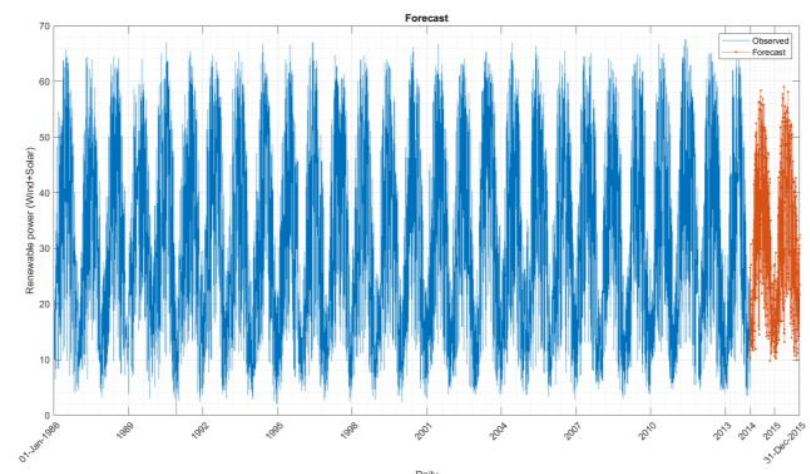

Figure 3: Predicted renewable energy production in two years advance for Spain with SVM.

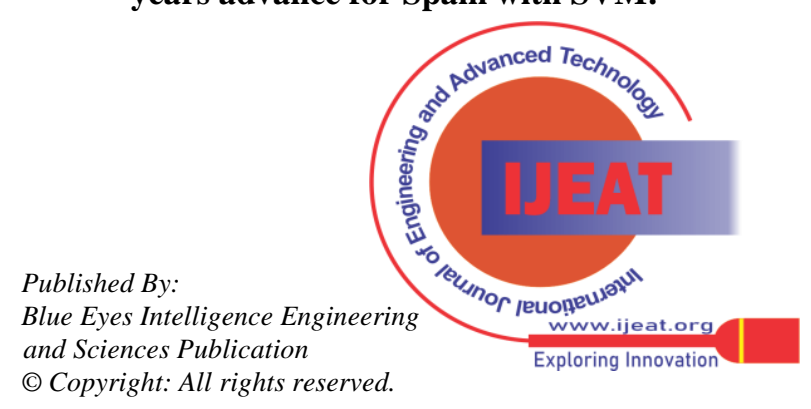




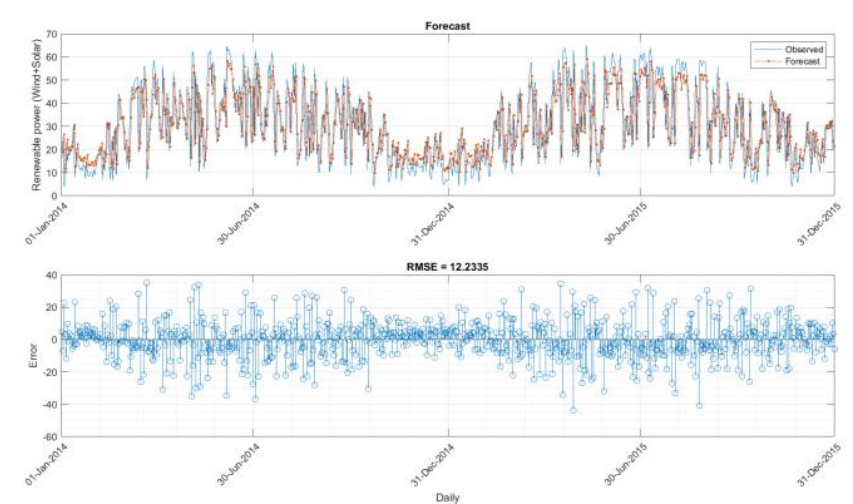

Figure 4: Predicted renewable energy productions in two years advance for Spain using SVM Method.

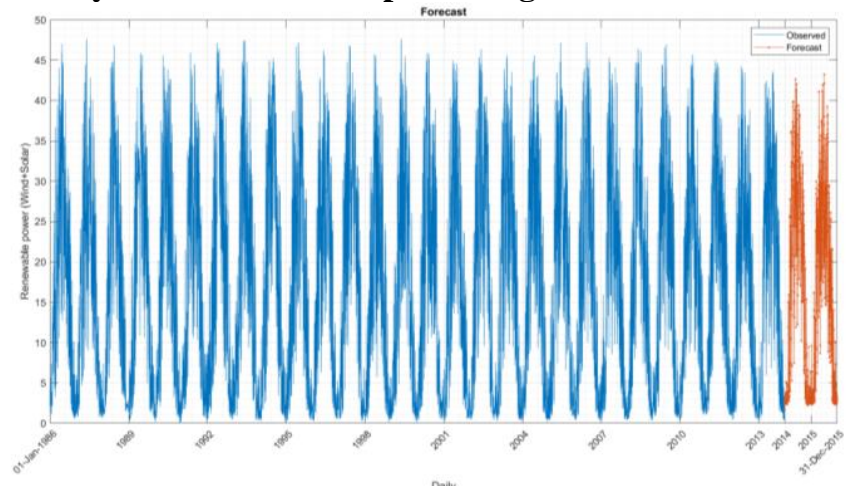

Figure 5: Predicted renewable energy production in two years advance for Sweden with $L R$.

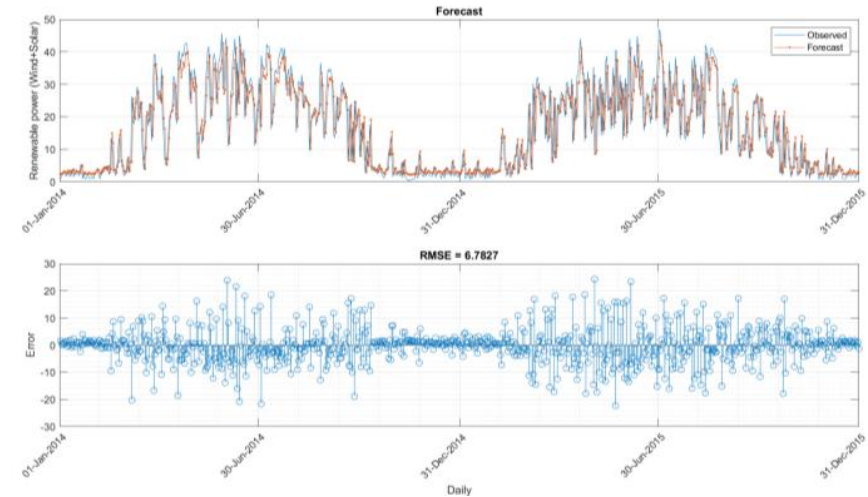

Figure 6: Predicted renewable energy productions in two years advance for Sweden using LR Method.

Figure 3 and Figure 5 show the predicted renewable energy in two years advance. We are interested to have a closer look on the between the predicted and original data. From Figure 4, we can see that the predicted data almost follow the original data. Similar pattern between predicted and original data is also observed in Figure 6. Please refer the following link for more visual result representation.

https://www.kaggle.com/kazimdshahiduzzaman/code-resu $\underline{\text { lt-ren }}$

\section{CONCLUSION}

In this work, we have proposed a very practical machine learning based algorithm call REN for forecasting two years of data in advance. This work can be considered as the benchmark for other related renewable energy production forecasting algorithm design. Due to the time constrain, this research work is only limited to consider three machine learning algorithms. But it is indeed is capable of optimize them before starting the prediction task. That is why this algorithm can generate sufficient accurate results. Besides, it also opens a new direction for the researchers in this direction to dig more to enhance the performance of the prediction algorithm and figure out more machine learning based algorithm to find the best fit. This work will be very helpful for the electrical load management engineers. The predicted result can be used in electrical efficient load distribution due to the prior knowledge of the renewable energy production. In this paper, we did not consider new renewable energy source or power station and the daily demand of electricity in prediction renewable energy. Therefore, in future there is a research scope to work on that.

\section{REFERENCES}

1. Ponta, L. Raberto, M. Teglio, A. Cincotti, "An Agent-based Stock-flow Consistent Model of the Sustainable Transition in the Energy Sector,' Ecol. Econ. vol. 145 (2018), pp. 274-300.

2. Matson, P. "The Sustainability Transition. Available," Issues in Science and Technology, vol. XXV, no. 4 (Summer, 2009). online: https://issues.org/matson/ (accessed on 29 September 2018).

3. Ahmad Tanveer, Chen Huanxin, "Deep learning for multi-scale smart energy forecasting,"' Energy: vol. 175 (2019), pp. 98-112.

4. Helbing Georg, Ritter Matthias, "Deep learning for fault detection in wind turbines,', Renewable and Sustainable Energy Reviews, vol. 98 (2018), pp. 189-198.

5. Chang GW, Lu HJ, "Integrating grey data preprocessor and deep belief network for day-ahead PV power output forecast, IEEE Trans Sustainable Energy, vol. 99. (2019), no. 1, pp. 185-194, doi: 10.1109/TSTE.2018.2888548.

6. Li Liang, Yuan Zhiming, Gao Yan, "Maximization of energy absorption for a wave energy converter using the deep machine learning,' Energy, vol. 165(2018), pp. 340-349.

7. Xiong Luo ; Jiankun Sun ; Long Wang ; Weiping Wang ; Wenbing Zhao ; Jinsong Wu ; Jenq-Haur Wang ; Zijun Zhang. "Short-term wind speed forecasting via stacked extreme learning machine with generalized chronotropy," Transactions on Industrial Informatics; vol. 14(2018), pp 4963-4971.

8. Bedi Jatin, Toshniwal Durga, "Deep learning framework to forecas electricity demand,” Apply Energy, vol. 238(2019), pp. 1312-1326.

9. Hua Haochen, Qin Yuchao, Hao Chuantong, Cao Junwei, “Optimal energy management strategies for energy Internet via deep reinforcement learning approach", Apply Energy, vol. 239 (2019), pp. 598-609.

10. Bates, J. M., and C. W. J. Granger. "The Combination of Forecasts." OR, vol. 20, no. 4, 1969, pp. 451-468. JSTOR, www.jstor.org/stable/3008764. Accessed 9 Nov. 2020.

11. Kaur, Amanpreet, Lukas Nonnenmacher, and Carlos FM Coimbra. "Net load forecasting for high renewable energy penetration grids," Energy, vol.114 pp. 1073-1084, 2016.

12. International Energy Agency. (2010), a. Technology Roadmap $\begin{array}{lll}\text { Concentrating } & \text { Solar } & \text { Power }\end{array}$ http://www.iea.org/publications/freepublications/publication/ technology roadmap- concentrating-solar-power.html

13. International Energy Agency. (2010), b. Technology Roadmap: Solar Photovoltaic Energyhttp://http://www.iea.org/publications/freepubl ications/publication/technologyroadmap-solar-photovoltaic-energy.htm

14. Gamal Aburiyana, Mohamed E. El-Hawary, "An Overview of Forecasting Techniques for Load, Wind and Solar Powers", 2017 IEEE Electrical Power and Energy Conference (EPEC), pp. 1-7,2017

15. Jang, Han Seung, Kuk Yeol Bae, Hong-Shik Park, and Dan Keun Sung, "Solar power prediction based on satellite images and support vector machine," IEEE Transactions on Sustainable Energy, vol.7, no. 3, p. 1255-1263, 2016.

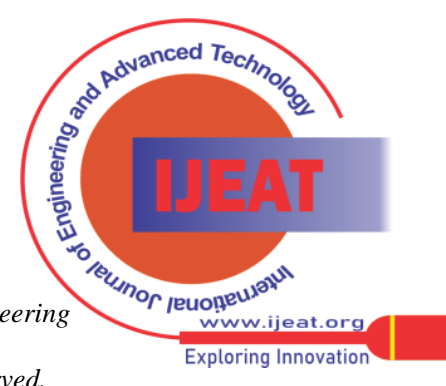


16. R. Jiao, X. Huang, X. Ma, L. Han, W. Tian, “A Model Combining Stacked Auto Encoder and Back Propagation Algorithm for Short-Term Wind Power Forecasting," IEEE Access, pp. 17851 - 17858,2018

17. Bhaskar Kanna, Sri Niwas Singh, "Long Term Wind Power Forecast Using Adaptive Wavelet Neura Network", 2016 IEEE Uttar Pradesh Section International Conference on Electrical, Computer and Electronics Engineering (UPCON), pp. 671-676, 2016

18. Gonzalez-Aparicio Iratxe, Huld Thomas, Careri Francesco, Monforti Fabio, Zucker Andreas," EMHIRES dataset Part II: Solar power generation", Science for Policy report by the Joint Research Centre (JRC), the European Commission's science and knowledge service, (2017).

19. Gonzalez-Aparicio Iratxe, Huld Thomas, Careri Francesco, Monforti Fabio, Zucker Andreas," EMHIRES dataset Part I: Wind power generation", Science for Policy report by the Joint Research Centre (JRC), the European Commission's science and knowledge service, (2016).

20. The Wind Power, "The Wind Power," 2015. [Online]. Available: http://www.thewindpower.net/. Accessed on 15.10.2019.

\section{AUTHORS PROFILE}

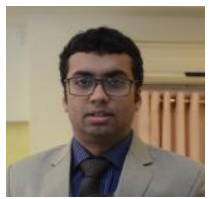

Kazi Md Shahiduzzaman, has completed his B.Sc. Eng in EEE from KUET, M.Sc. EE from Hochschule Bremen. Now, he is serving as an Associate Professor in JKKNIU, Bangladesh. He is currently working on different application scenarios of Machine learning techniques including image processing, sentiment detection, power forecasting, smart elderly care, cancer detection and prediction etc. He also has research interest in IoT, Free Space Optical Communication, Data Mining, Deep Learning etc.

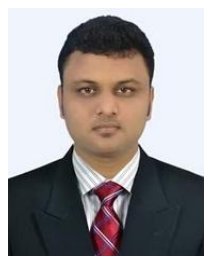

Md. Noor Jamal, is currently pursuing MSc in EIC at HUST, China. He has completed his B.Sc in EEE from IUBAT, Bangladesh. He has research interest in Machine learning based real-life application-oriented research work.

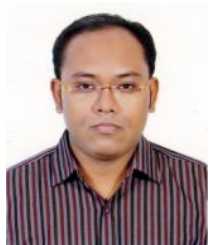

Md Rashed Ibn Nawab, received his B.Sc. in Computer and Communication Engineering Degree (2010) from International Islamic University Chittagong (IIUC), Chittagong, Bangladesh, and Master of Engineering in Computer Applied Technology Degree (2019) from Huazhong University of Science and Technology, Wuhan, China. His research interest includes Data Mining, Machine Learning, Deep Learning, and Blockchain. He has diversified experience working in the ICT industry for seven years.

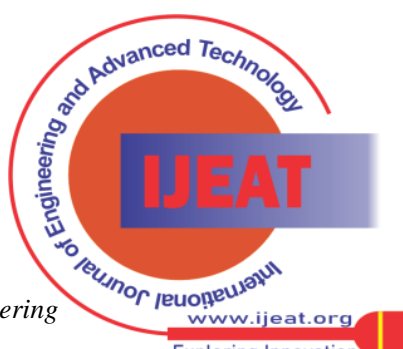


Renewable Energy Production Forecasting: A Comparative Machine Learning Analysis

Table 3: Performance comparison between LSTM, SVM and Linear Regression for predicting daily based renewable energy.

\begin{tabular}{|c|c|c|c|c|c|c|c|c|c|c|c|c|c|c|c|}
\hline & \multicolumn{5}{|c|}{ With LSTM } & \multicolumn{5}{|c|}{ With SVM } & \multicolumn{5}{|c|}{ With Linear regression } \\
\hline & $\begin{array}{c}\text { Mean } \\
\text { Forecasting } \\
\text { error }\end{array}$ & $\begin{array}{c}\text { Mean } \\
\text { absolute } \\
\text { error }\end{array}$ & $\begin{array}{c}\text { Mean } \\
\text { square } \\
\text { error }\end{array}$ & $\begin{array}{c}\text { Root } \\
\text { mean } \\
\text { square } \\
\text { error }\end{array}$ & $\overline{\text { Accuracy }}$ & $\begin{array}{c}\text { Mean } \\
\text { Forecasting } \\
\text { error }\end{array}$ & $\begin{array}{c}\text { Mean } \\
\text { absolute } \\
\text { error }\end{array}$ & $\begin{array}{l}\text { Mean } \\
\text { square } \\
\text { error }\end{array}$ & $\begin{array}{c}\text { Root } \\
\text { mean } \\
\text { square } \\
\text { error }\end{array}$ & Accuracy & $\begin{array}{c}\text { Mean } \\
\text { Forecasting } \\
\text { error }\end{array}$ & $\begin{array}{l}\text { Mean } \\
\text { absolute } \\
\text { error }\end{array}$ & $\begin{array}{c}\text { Mean } \\
\text { square } \\
\text { error }\end{array}$ & $\begin{array}{c}\text { Root } \\
\text { mean } \\
\text { square } \\
\text { error }\end{array}$ & Accuracy \\
\hline Austria & -1.17 & 14.257 & 298.45 & 17.276 & 31.3962 & -0.215 & 9.35 & 151.75 & 12.319 & 55.9117 & -0.0081 & 9.461 & 145.31 & 12.055 & 53.2831 \\
\hline Belgium & -6.041 & 16.153 & 411.978 & 20.297 & 14.9207 & -0.689 & 13.571 & 288.928 & 17 & 23.5229 & -0.418 & 13.614 & 277.115 & 16.647 & 14.9984 \\
\hline Czech & -1.14 & 9.478 & 136.296 & 11.675 & 39.312 & -0.184 & 9.0754 & 142.118 & 11.921 & 40.1905 & -0.087 & 9.21 & 137.202 & 11.713 & 33.1746 \\
\hline Finland & -0.291 & 2.368 & 10.502 & 3.241 & 16.7673 & 0.0304 & 2.134 & 9.364 & 3.06 & 35.636 & $\begin{array}{l}-0.0096 \\
\end{array}$ & 2.282 & 9.592 & 3.0971 & 36.5827 \\
\hline France & -3.71 & 18.582 & 523.386 & 22.878 & 72.4401 & -0.196 & 15.722 & 421.408 & 20.528 & 74.9215 & -0.405 & 15.864 & 420.8 & 20.513 & 74.2724 \\
\hline Germany & 2.141 & 27.699 & 1227.563 & 35.037 & 30.0202 & -0.415 & 18.835 & 589.945 & 24.289 & 60.9797 & -0.325 & 19.162 & 590.41 & 24.298 & 57.6045 \\
\hline Ireland & -0.198 & 2.492 & 9.845 & 3.138 & 39.4938 & -0.258 & 2.851 & 13.018 & 3.608 & 25.8326 & -0.04 & 2.863 & 12.778 & 3.575 & 17.1418 \\
\hline Netherland & -0.278 & 18.929 & 538.721 & 23.21 & 17.5804 & -0.647 & 13.743 & 315.362 & 17.758 & 26.5493 & -0.288 & 13.854 & 307.291 & 17.53 & 18.1775 \\
\hline Norway & -1.106 & 5.544 & 55.907 & 7.477 & 4.698 & -0.06 & 4.288 & 36.903 & 6.075 & 28.3009 & -0.0211 & 4.616 & 37.871 & 6.154 & 27.023 \\
\hline Poland & -7.131 & 22.163 & 766.1 & 27.679 & 30.9723 & -0.508 & 13.235 & 304.754 & 17.457 & 59.9749 & -0.398 & 13.55 & 303.871 & 17.432 & 54.4996 \\
\hline Sweden & -1.627 & 6.377 & 72.09 & 8.491 & 28.0659 & -0.14 & 4.83 & 46.001 & 6.783 & 44.0753 & -0.013 & 5.159 & 47.514 & 6.893 & 82.6851 \\
\hline Spain & -2.716 & 20.775 & 624.568 & 24.991 & 65.4913 & 0.535 & 9.845 & 163.072 & 12.77 & 82.9806 & -0.159 & 10.052 & 165.443 & 12.862 & 23.9148 \\
\hline
\end{tabular}

Retrieval Number: 100.1/ijeat.E26890610521 DOI:10.35940/ijeat.E2689.0810621 Journal Website: www.ijeat.org
Published By:

Blue Eyes Intelligence Engineering and Sciences Publication (C) Copyright: All rights reserved.

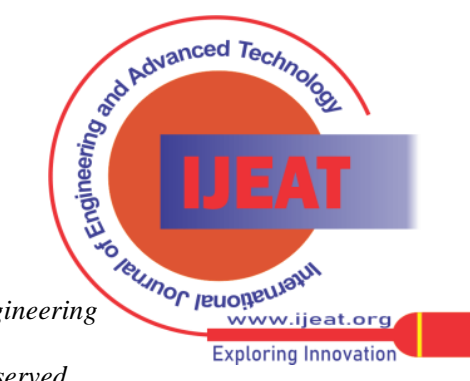

18 